\title{
LOS ESPACIOS MISTERIOSOS DE GUSTAVO ADOLFO BÉCQUER
}

I a poesía en verso de Bécquer es la historia de una aventura sentimental que incluye el destino del hombre desde antes de la cuna hasta más allá de la sepultura.

lin sus versos, sintió e imaginó que sentía; a sus sentimientos - tan auténticos los imaginados como los viviclos-, mezcló leves reflexiones filosúficas, pero siempre su sentir era dominante. Nhora bien, como sus scntimientos se alondaban en plenitud de intimidad, el tiempo y el espacio externos quedaban casi borrados frente al espacio y al ticmpo medidos por los latidos del corazón.

La historia sentimental que se nos canta en los versos de Bécquer se produjo de manera esencial, adentrada hasta lo más entrañable, y dejando mínimo margen a cualquier elemento circunstancial. Lis una pocsía en la que se hace abstracción del tiempo y del espacio, o se los reduce a datos secundarios que unas veces son indefinidos y otras son insignificantes. Lo único que cuenta sustantivamente es el sentimiento del poeta, posible en cualquier lugar $y$ en cualquier tiempo, sin que nada de lo demás llegue a tener importante significación; lo espacial y lo temporal se ofrecen más como sugerencia que como marco preciso de los hechos $\mathrm{y}$, en todo caso, reciben de la historia sentimental muchísimo más de lo que aportan a ella.

Iise tratamiento dado a espacio y tiempo viene a coincidir con uno de los tratamientos generales característicos de gran parte de la poesía romántica. Lo vago, lo indefinido, lo apenas sugerido facilitan el paso a lo misterioso $y$, dondequiera haya misterio, el vivir humano se redime de su servidumbre a lo real, a lo cotidiano. "Iiste lugar" y "este tiempo" valen siempre menos que "otro»; el tiempo y el espacio determinados valen siempre menos que los indefinidos. Y el máximo valor sólo podrá darse ya en el ámbito de lo misterioso. 
Puesto que el destino del hombre viene de no se sabe dónde y tampoco se sabe adónde va, puesto que hay que esforzarse mucho -y quizás nuestro esfuerzo resulte siempre baldio- por encontrarle un sentido a la vida, la sensación y el sentimiento de lo misterioso son consustanciales a la vida humana. Esta es, en síntesis, la situación inicial de Bécquer y otra razón de sus preferencias por los espacios misteriosos, únicos en verdacl compatibles con su naturaleza ensoñadora, con su afán espiritualista, como se muestra en la Rima VIII:

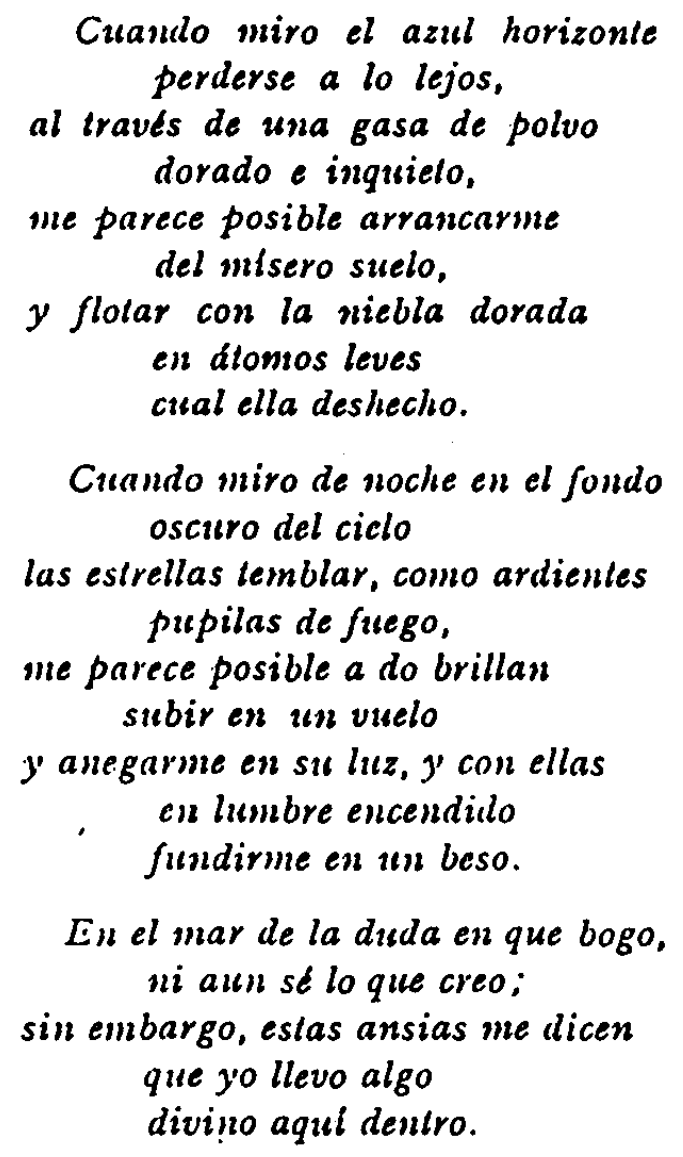

No son los espacios, obviamente, los que con su vaguedad y su misterio hacen que nazca ese "algo" dentro del poeta, sino que lo que en él hay de "más que humano» sólo puede identificarse con ellos, o sólo puede sentirse plenamente en ellos.

La compensación del desencanto del mundo real con la evocación, la prenatal memoria o la invención de un mundo fantástico que pueda ser habitado por el ideal, había acabado siendo en los románticos mera actitud estética; en Bécquer es inesquivable necesidad personal. In él los espacios reales se envuelven en un halo de misterio hasta perder su identidad. Ein cambio, los espacios misteriosos aparecen con fuerza sugeridora $y$, aunque nunca lleguen a ocupar el primer plano de aten- 
ción del poema, pueden alguna vez ser capaces de atraer la atención del lector, mientras no hay un solo ejemplo de espacio definido que sea válido en sí mismo como materia directa de poesía.

Dentro, pues, de la escasa importancia del espacio en la poesía de Bécquer, los lugares indefinidos, y más aún los misteriosos, son más abundantes que los definidos y concretos. Incluso en las contadas ocasiones en que la referencia espacial parece estar definida, no es válida para un lugar determinado, sino genérico: cn las cumbres, en las arenas, en los mares, en las riberas, en las tumbas, en las ruinas, en el torrente, cntre los árboles, en la corriente fresca (Rima V). Lo mismo que en esa ocasión sucede en la mayo- parte de las menciones que se hacen del mar, del cielo, del lago, de la playa, de la roca, del muro... Una sola vez se precisará geográficamente un lugar, pero aun entonces hay un plural que apunta a especie y no a (individuo": las cantabricas peñas de 1a Rima XII.

Obsérvese que esos nombres commes de lugares van casi sicmpre con artículo determinado, pero que no sirve de determinación concreta - ¿đué playa, qué lago, qué muro? - Sólo clentro de la plenitud intina podrán aparecer algunos lugares como únicos, inconfundibles c insustituibles: mi alcoba, mi venlana, mis balcones, mi lecho, mi fosa (Rimas XIV, XXVIII, XI,III y LXI) y tu balcón, lu jardin, el pórtico (le su casa (Rimas XVI, XXVII, XI y I,III), pero esa precisión no es más que mera apariencia. Los lugares no son considerados en sí mismos o se convicrten en símbolos... carecen de propia significación: su naturaleza apenas cuenta o adquieren una segunda naturaleza que invalida la que realmente les pertenece. Así, lo que se ve, en el ángulo de la alcoba, es la imagen de los ojos de la mujer amada (XIV): la ventana y los balcones soln términos secundarios en connotaciones no espaciales, sino temporales (XVI, XXVII, XXVIII y XLIII): el pórtico de la casa de la antigua amada es un lugar bien concreto, en el que sucedieron felices momentos de amor, pero los altos olmos le prestan sombra y mislcrio, $y$ el lugar vive en la memoria del poeta y no en experiencia coetánca, amén de acabar perdiendo su valor espacial para elevarse a testigo del amor (XL); el lecho del poeta es el de las horas de fiebre e insominio, así como su fosa es el lugar sobre el que nadie irá a llorar, con lo que lecho y fosa dejan también de ser lugares para convertirse en simbolos de soledad (LXI), igual que el ángulo oscuro del salón, en que está el arpa (VII) significa abandono: no el sitio en que algo o alguien está, sino la manera de estar alli.

Otro lugar concreto, el convento donde está una mujer amada, se torna también misterioso y acaba casi trasmutado en irrealidad, o, 
todo lo más, conserva una realidad levísima envuelta en fantasía; esa Rima LXX, en la que el poeta vaga en torno a las musgosas paredes del convento, tiene un origen dramático, aunque no lo sea su tratamiento. lil poeta se ha inventado unos personajes (él mismo y la monja que antaño fue su amada), para vivir así la experiencia sentimental que el poema canta. Los datos espaciales son "decorados" para un escenario y bien se advierte en cómo están presentados; lo mismo vuelve a suceder en la Rima LXXIV, que es complemento de la LXX.

Parecida conversión de concreto a abstracto, partiendo de un lugar definido pero inventado, se da en la Rima LXXVI, ante la gótica tumba, cuya estatua yacente parece más de una mujer dormida que de una mujer muerta. La imponente nave del templo bizantino - ya inicialmente alumbrada tan sólo por una indecisa y temblorosa luz- desaparece bajo la sugestión del espacio más misterioso: el habitado por el amor callado de la muerte y por el sueño tranquilo de la eternidad.

Repitamos que los espacios concretos no importan nunca primariamente y de alní se deriva su falta cle relieve en el poema como elementos susceptibles de recreación poética. P'uesto que no valen por sí mismos no merecen especial atención, no atracn la mirada lo bastante para que el lugar quede aislado, por muy fugacísima que fuera su impresión, cil la retina del lector.

Sólo se destacan cuankio sirven de términos de una comparación o cuando actúan como imágenes y 110 como realidades autónomas. $Y$ en esos casos, lo frecuente es que la comparación vaya a parar a lo indefinido, a lo misterioso: los elementos reales sirven para dar apoyo plástico a lo que es invisible, inefable... y aun inexistente fuera del mundo silencioso de la idea. Aquellas cumbres, riberas, ruinas, etc. de la Rima V "concretan" en la mente del lector ese

Espiritu sin nombre, indefinible esencia, yo vivo con la vida sin formas de la idea.

Yo soy el invisible anillo que sujela cl mundo de la forma al mundo de la idea.

Yo en fin soy ese espiriltl, desconocida esencia, perfume misterioso de que es vaso el poela. 
Advirtamos que lo que hay en las cumbres es nieve, con lo que el pocta apuntaba a las cumbres inaccesibles sólo habitadas por las nieves perpetuas que sugieren pureza y también misterio; que en las arenas hily fuego, sugiriendo los desiertos misteriosos; que en las corrientes hay ninfas duc juguetean desnudas, etc. De los demás elementos relacionados conl los espacios concretos de la citada Rima, sólo la yedra, habitante de liss ruinas, es algo perfectamente definido.

lin resumidas cuentas: loj espacios reales cuentan poquísimo para el pocta como material susceptible de reelaboración estética. Moralmente, sucede lo mismo, y el mundo, l ugar real del hombre, está desierto para él (LXV).

\section{Los misteriosos espacios}

Otra cosa sucede a éstos en la poesía en verso de Bécquer.

No sólo atraen la mirada, sino que la obligan a detenerse, a tomar consciencin de lo mirado. Ver cede el paso a contemplar. No se limitan a ser datos secundarios: actían reflejando o intensificando los estados de inimo y se personalizan en el pensamiento del poeta una y otra vez, micuntras cule de los lugares concretos sólo el pórtico, la casa y el camino bordeado de olmos, de la citada Rima XL, habian aparecido bajo una prosopopeya (una especial animación, pues no se les hace hablar: se les pide (juc callen).

Por su índole, por su función y por la intensidad con que aparecen, los espacios misteriosos pueden ser agrupados en cuatro categorias: a) lus (que no son misteriosos en sí mismos; el misterio les llega del estado de ánimo o de consciencia del poeta; b) los que no siendo tampoco necesariamente misteriosos por sí mismos, adquieren tal condición al ser asociados con el destino del hombre; c) los que son misteriosos por sf mismos, o son susceptibles de aparecer como tales para el hombre madio; d) los espacios inexistentes.

I a primera categoría es aludida expresamente por Bécquer en la única ocasión en que llevó a un verso la palabra espacio. Ińn la primera estrofa de la Rima LXXI, nos dice:

$$
\begin{gathered}
\text { No dormia; vagaba en ese limbo } \\
\text { en que cambian de forma los objelos, } \\
\text { misleriosos espacios que separan } \\
\text { la vigilia del sueno. }
\end{gathered}
$$

Iis un mundo espectral, ligado a la noche, a la fiebre, al insomio y a la soledad. Cuanto existe cambia en él de forma, se envuelve en mis- 
terio. İsos espacios misteriosos que separan la vigilia del sueño hacen que la consciencia se cambie en intuición. Son dos formas de conocimiento, dos luces, pero la que prevalece en el poema es la que está en el límite extremo de ese limbo, allá donde ya va a comenzar el sueño:

De la luz que entra al alma por los ojos

los parpados velaban el reflejo.

pero otra linz el mundo de visiones

alumbraba por dentro.

Iil misterio de esos espacios ha nacido en el poeta, aunque no en su voluntad ni en su razón.

Iin esta primera categoria habría que incluir los "paisajes que aparecen como al través de un tul" (III), porque el velo no está ahí, no es real como "la gasa de polvo" de la Rima VIII. I,os paisajes no son vistos, sino que aparecen como vistos al través de un tul: el velo está en el contemplador. I'ales paisajes son uno de los varios términos comparativos de la inspiración, único (pue es pasivo, estático, mientras todos son activos y dinámicos. Como su misión es una caracterización poética de la inspiración, la nota común a todos es lo misterioso (por indefinido o informe o deforme o inefable); sin embargo, mientras en los demás resicle el misterio, en los paisajes se adquiere nada más descle la perspectiva en que están contemplados. La manera de ver importa más que lo visto.

Ese imaginario velo de tul que trasforma el paisaje reside en el estado de ánimo del poeta. De allí mismo surgirán otras fuerzas capaces de producir más profundas trasformaciones del espacio. Asf, cuando en la Rima X el poeta se da cuenta del paso del amor, el cielo y la tierra reflejan con júbilo el mismo deslumbramiento que él siente. El orden de los gozosus signos está bellamente alterado, figurando al final el que es principio y causa de los demás.

El mismo deslumbramiento y con la misma potencia trasformadora se da en la Rima XVIII, trascendiendo esta vez lo espacial: que la amada haya mirado al poeta es causa de que los cielos y la tierra le sonrían, de que el sol le llegue al fondo del alma... y, sobre todo, de su exultante fe en Dios.

Lil amor pone cada cosa en su sitio y la vida del poeta se llena de plenitud aqui y ahora, pero todo ese orden tiene un origen misterioso. I,os lugares del anor son los mismos de la vida cotidiana, pero reciben una luz nueva que los hace aparecer distintos, milagrosos, misteriosos. Cuando la luz-gozo acabe convirtiéndose en penumbra-dolor, la potencia trasformadora seguirá siendo la misma. 
La segunda categoría es menos frecuente en Bécquer. Espacios que se hacen nisteriosos al ser asociados con el destino del hombre; lugares que, al no tener una localización determinada, o al estar sometidos a un peculiar dinamismo sin principio ni fin aparentes, se convierten en términos comparativos, o en símbolos, del complejo de realidad y misterio que es muestro destino.

Igual que éste, se corresponden con las grandes interrogacioncs ¿de clóncle?, ¿adónde? y se reiteran en la buena poesía y en la mala como fáciles tópicos. Ėn la de Bécquer se dan con tales formulaciones en la romántica Rima II: el ignorado sitio en que se clavará la saeta arrojada al azar, el surco en que caerá la hoja seca arrebatada por el vendaval, la playa ignorada a donde irá a parar la ola gigante empujada por cl viento... son espacios comparables al ignorado punto en qué irá a parar el destino del hombre, porque la vida del hombre es arrastrada por una fuerza ciega y fatal, lo mismo que la hoja seca $y$ la ola, con las que el poeta ha podido comparar su vida.

Iin esa Rima las interrogaciones están diluidas a lo largo de las cinco estrofas; cuando el tema reaparece en otra Rima, la LXVI, el tratamiento se intensifica y alcanza el más desgarrado y bello patetismo, provocado por las dos preguntas que ahora, formuladas, iniciarán respectivamente las dos estrofas del poema:

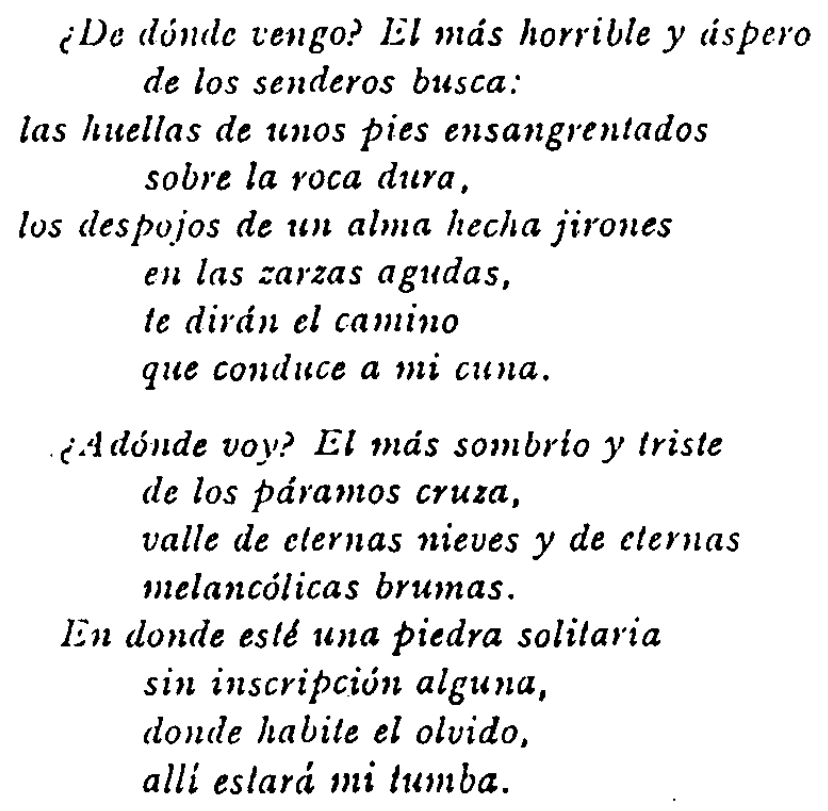

Iil espacio propio del hombre no es un lugar en que se está: es un camino en que se sufre. $Y$ aunque se sabe que ese camino tiene un punto final seguro, tal sabiduría es inútil para contestar la pregunta ¿adónde? (Por otra parte, el punto final del largo y doloroso camino que en esa 
Rima va de la cuna del poeta hasta su tumba es un singular espacio del que nos ocuparemos más adelante.)

Con los espacios de esta segunda categoría se relacionan en el juego de comparaciones los elementos que se repiten incesantemente sin que sea posible un conocimiento singularizador de los mismos; la ola que va silenciosa a expirar en la playa, la ráfaga de viento, las ondas de niebla, las sombras nocturnas, conficren al espacio una nota de misterio que no procede de éste ni de aquéllos, sino que surge en la doble iluminación comparativa: esas imágenes ayudan a sentir el misterio del destino humano y reciben de él su tono misterioso.

La comparación se acentúa con gran fuerza poética, de manera que la vida del poeta - la vida del hombre-, los espacios ignorados y los terribles inpulsos aparecen perfectamente fundidos, al reiterarse en la Rima LII:

Olas giganles que os rompeis bramando

en las playas desierlas y remolas, envicello entre la sabana de espitinas, ¡llevadine con vosolvas!

Rajagas de huracain, que arrebaldis del alto bosque las marchilas hojas, arrastrailo en el ciego torbellino, illevadme con vosolras!

Nubes de tempestad que rompe el rayo $y$ en fuego orndis las desprendidas orlas, arrebatado entre la niebla oscura, ¡llevadine con vosolras!

Llevadme, por piedad, a donde el vérligo con la razón me arranque la menoria. iPor piedadl , Tengo miedo de quedarme con mi dolor a solas!

La playa desconocida, el viento o la sombra nocturna no contienen necesariamente misterio. Pero las playas desiertas y remotas, el ciego torbellino del huracán y el vacío cósmico sugieren misterio por sí mismos; con ellos entramos en la tercera categoría.

Por de pronto, el misterio es ya en sí un venero de poesía y ese misterio puede residir en todo cuanto escape al conocimicnto del hombre. Los espacios que no pueden ser medidos son susceptibles de ser pensados como infinitos; son, desde luego, misteriosos y por tanto especialmente aptos para servir a Bécquer de material poético secundario: 


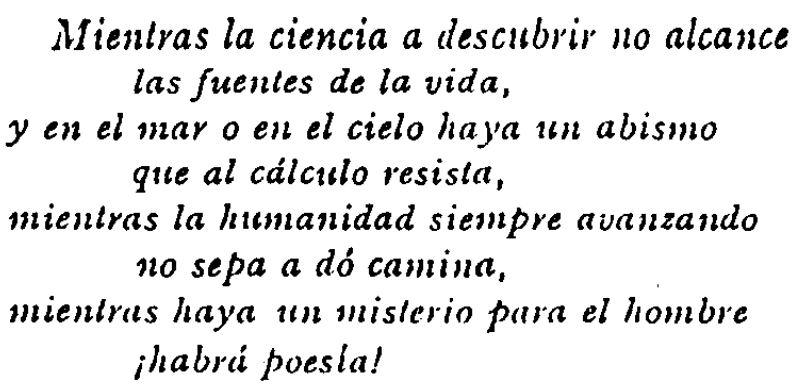

No es que la poesía pueda vincularse sólo a esos espacios; sicndo clla misma perfume misterioso, puede tener residencia en espacios concretos -aunque sicmpre con la salvedad que hicimos al referirnos a esta misma Rima V-, pero su verdadero mundo es el otro:

yo nado en el vaclo,
del sol tiemblo en la hognera,
palpito entre las sombras
y flolo con las nieblas.

I a máxima claridad, expresadar en el verso segundo, es compatible con el misterio o la oscuridad de los otros tres: vacío cósmico, sombras, nieblas... a los que se añaden, más adclante, las profundas cavernas donde nunca penetra el sol y que, por ser el lugar en que los gnomos guardan sus tesoros, se convierten en mezcla de lugar misterioso existente y de lugar misterioso inventado por la fantasía.

La sombra y la noche envuelven en misterio algunos espacios y los objetos que los ocupan. Aunque ese misterio se desvanezca con la luz del día, espacios y objetos han sido auténticamente misteriosos y no por exclusiva receptividad del poeta como los espacios de la primera categoría, sino con validez para el tipo humano medio; los espacios aparecen como misteriosos, aunque no lo sean permanentemente, pero esa apariencia es válida para la mayoría de los hombres y forma una cualidad propia de ese espacio, algo netamente distinto del limbo de la Rima LXXI.

I os espacios cuyo misterio consiste en la imposibilidad humana de medirlos clarán a Bécquer excelente base para una diversificación hiperbólica: las profundas simas de la tierra y del cielo son espacios misteriosos por ser hondos y ser oscuros (es decir, desconocidos), pero es más hondo y más negro (lo oscuro es ahora valoración ética) el corazón de cicrta mujer (LXVII).

Aquí tenemos el ejemplo que resume la utilización del espacio en Bécquer. Y no sólo el espacio: todo en la poesía ell verso de Bécquer 
viene a parar a lo íntimo del ser, tópicamente expresado con la palabra corazón. Se cierra el círculo, pues todo había nacido allí.

La cuarta categoría es la de los espacios inexistentes, pura imagen y abstracción completa; se da con valor simbólico o metafórico.

linn la estrofa final de la Rima VIII, la duda es mar en que el poeta, nave de máxima aventura, boga sin rumbo. De igual manera, el poeta es onda sonante en mar sin playas (XV) y quizás hay un espacio al que van a parar los amores olvidados (XXXVIII).

Iin la estructura de la Rima LXXV, las cinco primeras estrofas son interrogaciones a las que se responde, indirectamente pero con firmeza, en la estrofa sexta y última. Durante el sueño chuye el espiritu de la caircel del cuerpo? Y si es así, ese espíritu - HUESPLD DE LAS NIEBLAS- ¿sube a la región vacia, a encontrarse con otros espiritus?, ¿habita, durante breves horas, en el mundo silencioso de la idea?

Los espacios del sueño pertenecen a un mundo de visiones; no sabe el pocta si ese mundo vive fuera o va dentro de nosolros, pero cree tener pruebas de su realidad. I a poetización de ciertas intuiciones misteriosas - sé que conozco a muchas secules a quienes no conozco- no se liga a remembranzas de una vida anterior o de un perdido mundo ideal, sino a experiencias actuales localizadas en los espacios inexistentes del sueño.

Iintre los espacios reales más o menos indefinidos de la Rima V se encuentran otros inexistentes:

Yo sé de esas regiones

a do un rumor $n o$ llega

y donde informes astros

de vida un soplo esperan.

Podríamos ceder a la tentación de colocar en esta cuarta categoría un espacio perfectamente delimitado: el lugar donde el poeta pensaba que iba a estar su tumba. En su radical, aunque resignado, pesimismo, la sitúa en un espacio cuyas connotaciones trasforman el lugar concreto de una sepultura en un espacio imaginario tan inexistente, que sólo' estará habitado por el olvido (L,XVI).

Todavía más allá del sepulcro, hay un espacio inexistente que es propio de la muerte; a sus puertas se sentará el poeta para esperar a que la amada llegue.

\author{
alli donde el sepulcro que se cierra \\ abre una eternidad, \\ todo cunnto los dos hemos callado \\ all lo hemos de hablar.
}


ALII; el adverbio señala un lugar donde todo encuentro es imposible; espacio inexistente donde se cierra el tiempo del hombre $y$ se abre la eternidad, el más terriblemente misterioso. 'También él ha de seguir la suerte de todos los demás espacios y estar plenamente subordinados al amor. $O$ al clolor de amor, que constituye la más alta materia poética becqueriana.

ILIIEHONO-NIANULI, GIL 